\title{
Usefulness of Computerized Tomography Scan for the Detection and Evaluation of Acute Pancreatitis
}

\author{
G. Srirama Murthy ${ }^{1}$, R. Somasekhar ${ }^{2}$ \\ ${ }^{1}$ Associate Professor, Department of Radiology, Shri Sathya Sai Medical College and Research Institute, Kancheepuram \\ District, Tamilnadu, ${ }^{2}$ Assistant Professor, Department of Radiology, Shri Sathya Sai Medical College and Research Institute, \\ Kancheepuram District, Tamilnadu, India.
}

Corresponding author: Dr. R. Somasekhar, Assistant Professor, Department of Radiology, Shri Sathya Sai Medical College and Research Institute, Kancheepuram District, Tamilnadu, India

DOI: http://dx.doi.org/10.21276/ijcmsr.2020.5.1.27

BY-NC-ND

How to cite this article: G. Srirama Murthy, R. Somasekhar. Usefulness of computerized tomography scan for the detection and evaluation of acute pancreatitis. International Journal of Contemporary Medicine Surgery and Radiology. 2020;5(1):A123-A127.

\section{A B S T R A C T}

Introduction: Acute pancreatitis is one of the most common diseases of the gastrointestinal tract. Imaging by CT scan helps in diagnosing severity of acute pancreatitis including the presence of pancreatic necrosis as well as local and systemic complications. Current study aimed to study the use of CT scan for the detection and evaluation of acute pancreatitis.

Material and Methods: A total of 110 patients diagnosed clinically with acute pancreatitis were studied for patient demographics, clinical presentation, etiology and CT scan findings.

Results: A ttal of 110 patients with age ranging from 15 years to 60 years were studied. The male to female ratio was 2.1:1. Most (59\%) of the cases were in the 41 to 50 years age. Epigastric pain and vomiting were the most common clinical features. Gall stones and alcoholism were the most common etiological factors for acute pancreatitis. CT findings showed diffuse enlargement in $43.6 \%$ cases, and irregular contour in $63.6 \%$ cases. Ascites and pleural effusion were noted in $31.8 \%$ cases. Balthazar's CTSI system gave better results than the Ranson's criteria.

Conclusion: Acute pancreatitis commonly affects adult males. CT scan plays an important role in diagnosing acute pancreatitis and Balthazar's CTSI system is advantageous over the Ranson's criteria system. The CT modality gives information on the severity and extent of the inflammatory process and thereby helps in decision making for patient management.

Keywords: Acute Pancreatitis, CT Scan in Acute Pancreatitis, CT Scan in Pancreatic Necrosis

\section{INTRODUCTION}

Acute pancreatitis is one of the most common diseases of gastrointestinal tract (GIT), leading to tremendous emotional, physical, and financial burden. ${ }^{1}$

Acute pancreatitis (AP) is a complex clinical condition with majority of patients and in approximately 20\% becomes clinically very severe with significant mortality. ${ }^{2}$ Clinically severe patients require admission to intensive care unit (ICU), where close monitoring and treatment with aggressive fluid resuscitation are a must. ${ }^{3}$ Clinically, acute pancreatitis is diagnosed in patients with two of the following three features: (a) sudden onset of upper abdominal pain, (b) serum amylase and/ or lipase levels more than three times the upper limit of normal, and/or (c) abdominal computed tomography (CT) scan or ultrasound scan having characteristic findings. ${ }^{4,5}$ Diagnosis of acute pancreatitis is made by combination of clinical presentation, laboratory investigations and imaging. Serum amylase, lipase, liver function tests, serum electrolytes with blood gas analysis are the commonly performed laboratory investigations which help to grade the severity and prognosis of acute pancreatitis based on several clinical criteria including Ranson's criteria. ${ }^{6}$
Imaging plays a major role in diagnosing severity of acute pancreatitis including the presence of pancreatic necrosis as well as local and systemic complications. It also serves as a guide for therapeutic intervention and response to therapy. ${ }^{7}$ Modified CT severity index is used to detect extent of necrosis and various local and extra pancreatic complications. ${ }^{8}$

Two commonly used CT scoring systems are the CT severity index (CTSI), and modified CT severity index (MCTSI), proposed by Mortele et $\mathrm{al}^{9}$ and require the use of intravenous (IV) contrast agents to determine the presence and extent of pancreatic necrosis, as well as inflammatory changes and local and/or extrapancreatic complications.

Modified Computed Tomography Severity Index (MCTSI) has been introduced which differs from the Computed Tomography Severity Index (CTSI) by including the presence of extra pancreatic complications and grading the peripancreatic fluid collection in terms of presence or absence instead of the number of fluid collections. The grading of necrosis is also different in this system. ${ }^{9}$

In the cases with acute pancreatitis, CT examination should be performed if the clinical diagnosis is uncertain, clinical findings suggest severe acute pancreatitis (Ranson score $\geq 3$, APACHE II score $\geq 8$ ), or there is suspicion of necrotizing 
pancreatitis, and for patients who do not improve clinically within 72 hours of the initial conservative medical therapy or for patients who demonstrate improvement during the initial medical therapy but then manifest acute change in clinical status with fever, pain, decrease in hematocrit or hypotension, and also when any complication is suspected..$^{10,11}$

CT findings of acute pancreatitis depend on the severity and extent of the inflammatory process. A CT scan which is performed within the first 48 hours of the onset of symptoms may be completely normal. CT findings of acute pancreatitis include enlargement of the pancreas (localised or diffuse), ill defined parenchymal contours, decrease in density and inhomogeneity of the pancreatic parenchyma and there may also be fluid collections in the peripancreatic region. The inflammatory reaction can produce increased attenuation of the peripancreatic adipose tissue commonly described as "stranding". 12-14

Current study aimed to study the use of CT scan for the detection and evaluation of acute pancreatitis.

\section{MATERIAL AND METHODS}

Permission was taken from the institutional ethical committee.

Informed consent was taken from all the patients included in the study.

This was a prospective observational study done on 110 patients diagnosed with acute pancreatitis. Study was conducted in the department of Radiodiagnosis at Shri Sathya Sai Medical College and Research Institute, Kancheepuram district, Tamilnadu, India for one year, ie, from March 2018 - April 2019

\section{Inclusion criteria}

- Patients willing to participate in the study

- Both the genders

- Patient age between 10 to 60 years

- Clinically diagnosed cases of acute pancreatitis

- History of Trauma

- Laboratory findings suggestive of acute pancreatitis

- Normal serum creatinine level

\section{Exclusion criteria}

- Patients not willing to participate in the study

- Age below 10 years and above 60 years

- Pregnant women

- High serum creatinine level where contrast can not be given

All the cases included in the study were from the out patient department of General Surgery and indoor admitted patients under department of General Surgery. Once the patients were clinically diagnosed as acute pancreatitis, then they were referred to department of Radiology for Imaging studies as part of patient work-up.

A thorough clinical examination was done including history taking, onset of symptoms, past history of similar complaints, history of cholelithiasis, alcohol intake, or smoking. Local and systemic examination was done. Laboratory investigations were requested from the primary consulting physician and included hemogram, urine analysis, serum amylase, serum lipase, serum creatinine level, lipid profile (mainly triglyceride), and random blood glucose. All the patients were subjected to USG abdomen and findings were noted. All the patients were subjected to CT scan and the following points were noted: the pancreatic parenchyma affection (bulky, edematous, necrotic, focal, or diffuse); peripancreatic region (stranding, single peripancreatic collections, or pseudocysts); GB or common bile duct stones; biliary and pancreatic ducts; masses in the pancreas or ampulla; and extrapancreatic ascites, pleural effusion lung bases, and intestinal loops.

In the department of Radiodiagnosis, the procedure was explained to the patients beforehand. The mean duration between onset of symptoms and CT scan procedure was 7 days (and within 15 days) as by that time necrosis can be detected very well.

Equipment used: The CT machine that was used is Toshiba Aquilion (160 slices). The contrast used was water soluble and nonionic (Omnipaque) administered at $300 \mathrm{mg} / \mathrm{ml}$ through intravenous injection.

After collecting all data from CT, we made grading of acute pancreatitis into five grades $(\mathrm{A}, \mathrm{B}, \mathrm{C}, \mathrm{D}$, and $\mathrm{E})$, and this grading was done according to the texture of pancreas and peripancreatic fluid in the abdomen.

Grading of Acute Pancreatitis with CT by Balthazar's system $^{9}$ as given below was done:

Grade A Laboratory and clinical evidence of pancreatitis with normal pancreas (score 0 ).

Grade B Showed bulky pancreas (focal or diffuse) with no peripancreatic changes (score 1).

Grade C Showed peripancreatic stranding (score 2).

Grade D Showed single peripancreatic fluid (score 3).

Grade E Showed two or more than two pockets of fluid collection or gases on the retroperitoneal space (score 4).

Ranson's clinical criteria were followed to categorize the cases and both systems of Ranson's criteria and Balthazar's CTSI grading were compared.

\section{RESULTS}

There were a total of 110 patients in the study. The male to female ratio was 2.1:1. The patient age ranged from 10 years to 60 years. The youngest patient was 15 years and the oldest patient was 60 years old (table-1).

In the present study age group distribution included from 10

\begin{tabular}{|l|c|c|}
\hline Age in years distribution & No. of cases & Percent (\%) \\
\hline $10-20$ & 01 & $0.9 \%$ \\
\hline $21-30$ & 03 & $2.7 \%$ \\
\hline $31-40$ & 21 & $19.0 \%$ \\
\hline $41-50$ & 65 & $59.0 \%$ \\
\hline $51-60$ & 20 & $18.1 \%$ \\
\hline Total & 110 & $100 \%$ \\
\hline \multicolumn{2}{|c|}{ Table-1: Showing age distribution } \\
\hline
\end{tabular}

\begin{tabular}{|l|c|c|}
\hline Gender & No. of cases & Percent (\%) \\
\hline Males & 75 & $68.1 \%$ \\
\hline Females & 35 & $31.8 \%$ \\
\hline Total & 110 & $100 \%$ \\
\hline \multicolumn{2}{|c|}{ Table-2: Showing gender-wise distribution of the cases } \\
\hline
\end{tabular}




\begin{tabular}{|l|c|c|}
\hline Clinical features & No. of cases & Percent (\%) \\
\hline Epigastric pain & 30 & 27.2 \\
\hline Epigastric pain + vomiting & 45 & 40.9 \\
\hline Nausea & 20 & 18.1 \\
\hline Vomiting & 10 & 9.0 \\
\hline Tenderness & 05 & 4.5 \\
\hline Total & 110 & $100 \%$ \\
\hline \multicolumn{2}{|c|}{ Table-3: Showing clinical features } \\
\hline
\end{tabular}

\begin{tabular}{|l|c|c|c|}
\hline \multirow{2}{*}{ Balthazar's CT grade } & \multicolumn{2}{|c|}{ CTSI } & \multirow{2}{*}{ Total } \\
\cline { 2 - 3 } & Mild & Severe & \\
\hline B & 17 & 11 & 28 \\
\hline C & 29 & 13 & 42 \\
\hline D & 18 & 7 & 25 \\
\hline E & 11 & 4 & 15 \\
\hline Total & 75 & 35 & 110 \\
\hline
\end{tabular}

Table-7: Comparison between Balthazar's CT Grading and CTSI Correlation

\begin{tabular}{|c|c|c|}
\hline CT signs of acute pancreatitis & No. of cases & Percent (\%) \\
\hline \multicolumn{3}{|l|}{ Gland } \\
\hline Normal & 20 & $18.1 \%$ \\
\hline Diffuse enlargement & 48 & $43.6 \%$ \\
\hline Focal enlargement & 42 & $38.1 \%$ \\
\hline \multicolumn{3}{|l|}{ Contour } \\
\hline Regular & 40 & $36.3 \%$ \\
\hline Irregular & 70 & $63.6 \%$ \\
\hline \multicolumn{3}{|l|}{ Density } \\
\hline Isodense & 12 & $10.9 \%$ \\
\hline Focal hypodensity & 70 & $63.6 \%$ \\
\hline Generalized hypodensities & 20 & $18.1 \%$ \\
\hline Distorted architecture & 8 & $7.2 \%$ \\
\hline \multicolumn{3}{|l|}{ Necrosis } \\
\hline$<30$ & 32 & $29.0 \%$ \\
\hline $30-50$ & 12 & $10.9 \%$ \\
\hline$>50$ & 12 & $10.9 \%$ \\
\hline Ascites & 35 & $31.8 \%$ \\
\hline Pleural effusion & 35 & $31.8 \%$ \\
\hline
\end{tabular}

\begin{tabular}{|l|c|c|}
\hline Etiology of acute pancreatitis & No. of cases & Percent (\%) \\
\hline Gall stones & 35 & $31.8 \%$ \\
\hline Alcoholism & 30 & $27.2 \%$ \\
\hline Trauma & 04 & $3.6 \%$ \\
\hline Idiopathic & 22 & $20 \%$ \\
\hline Drug induced & 15 & $13.6 \%$ \\
\hline Hyperlipidemia & 04 & $3.6 \%$ \\
\hline Total & 110 & $100 \%$ \\
\hline \multicolumn{2}{|c|}{ Table-5: Showing etiology of acute pancreatitis } \\
\hline
\end{tabular}

\begin{tabular}{|l|c|c|c|c|}
\hline Grade & \multirow{2}{*}{ Points } & \multicolumn{2}{|c|}{ Necrosis } & Severity \\
index \\
\cline { 3 - 4 } & & Percent & $\begin{array}{c}\text { Additional } \\
\text { points }\end{array}$ & \\
\hline A & 0 & 0 & 0 & 0 \\
\hline B & 1 & 0 & 0 & 1 \\
\hline C & 2 & $<30$ & 2 & 4 \\
\hline D & 3 & $30-50$ & 4 & 7 \\
\hline E & 4 & $>50$ & 6 & 10 \\
\hline \multicolumn{2}{|c|}{ Table-6: Balthazar's Grading of Acute Pancreatitis and CT } \\
severity index \\
\hline
\end{tabular}

years to 60 years.

Majority of patients were among 41to 50 years having (65/110) 59.0\% cases,

Next common age group was that of 31-40 years with 19\%

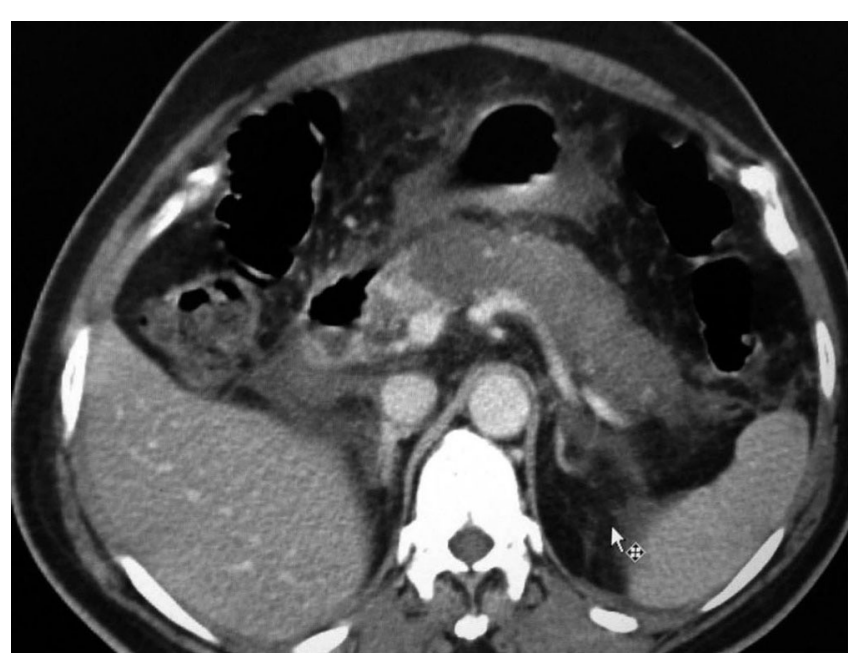

Figure-1: CT post contrast study shows acute pancreatitis with $>80 \%$ necrosis

\section{(21/110) cases.}

In the present study majority of the patients were males $68.1 \%(75 / 110)$ as compared to females $31.8 \%$ (35/110). The male to female ratio was 2.1:1 (table-2).

In the present study most common clinical presentation was of epigastric pain and vomiting seen in $40.9 \%(45 / 110)$ cases, followed by epigastric pain only in $27.2 \%(30 / 110)$ cases (table-3).

In the present study, $\mathrm{CT}$ findings showed diffuse enlargement in $43.6 \%$ cases, and irregular contour in $63.6 \%$ cases. Ascites and pleural effusion were noted in $31.8 \%$ cases (table-4). In our study, amylase level was raised in 59\% cases, whereas lipase level was raised in $80 \%$ cases (fig-1).

In the present study, most common etiological factor was gall stones and was seen in 31.8\% (35/110) cases, next common factor was alcoholism and was seen in $27.2 \%(30 / 110)$ cases (figure-5).

A CT Severity index (CTSI) of less than 5 is taken as mild acute pancreatitis and CTSI of $>5$ is considered as severe degree of acute pancreatitis (figure-6).

In our study, there were 75 cases of mild acute pancreatitis as per Balthazar's CTSI system. Out of 75 cases, 64 cases (85.3\%) correlated well for Ranson's criteria for mild severity. Remaining 11 (14.6\%) cases were graded as severe as per Ranson's criteria but were actually mild category on CTSI score (figure-7).

In our study, 35 (31.8\%) cases were in severe category as per Balthazar's CTSI system. Of these 35 cases, 29 (82.1\%) correlated well with Ranson's criteria for severe disease process. The remaining $6(17.1 \%)$ cases which were 
considered as severe by CTSI were thought of as mild on Ranson's criteria.

Duration of hospital stay: The median duration of hospital stay was 8 days (range was from 3 to 71 days), and $43.3 \%$ cases had a hospital stay of more than 10 days. Seventeen (40.0\%) patients had clinical evidence of infection, whereas only 3 out of these 17 showed radiological evidence of infection. Intervention was required in $15(25 \%)$ cases. Out of 60 patients, 53 recovered while 7 died. All the patients who died had evidence of infection. Moreover, of all the patients with evidence of infection, 7/17 (41\%) cases died.

There was a significant association $(\mathrm{P}<0.001)$ between evidence of infection and mortality. All the patients who died had persistent organ failure.

\section{DISCUSSION}

Comparative studies based on sample size: The present study included 110 cases with clinical diagnosis of acute pancreatitis. Bader HA et $\mathrm{al}^{15}$ in their study included 100 patients. In the study by Tripathi $\mathrm{BN}$ et $\mathrm{al}^{16}$ there were a total of 91 patients. In the study by Jeevangi BA et $\mathrm{al}^{17}$ there were 53 cases of acute pancreatitis.

Comparative studies based on age distribution: In the present study, the patient age distribution was from 10 years to 60 years. Majority of the patients were among $41-50$ years ie, $59.0 \%(65 / 110)$. Next common age group were among 31 to 40 years ie $19 \%(21 / 110)$.

In Bader HA et $\mathrm{a}^{15}$ study, age ranged from 9 to 83 years, with a mean of 41.89 years. The highest prevalence was among 40 to 50 years age group.

In Tripathi $\mathrm{BN}$ et ${ }^{16}$ study, the youngest patient was 12 years old and the oldest was 84 years old. Majority of the patients were between the ages of 21 to 40 years.

In Jeevangi $\mathrm{BA}$ et $\mathrm{a}^{17}$ study, the mean age group was 44 years and most of the patients belonged to the age group 31-40 years.

Sawarkar $\mathrm{K}$ et $\mathrm{al}^{18}$ found that majority of participants belonged to 31 to 40 years of age group ( 23 cases), followed by 12 cases in age group of 21-30 years, 7 cases in 41 to 50 years and 4 cases in 51 to 60 years of age group. In the present study, most of our cases belonged to the 41 to 50 years age group.

Our findings compare well with those of the above authors.

Gender distribution: In the present study, majority of the patients were males $68.1 \%(75 / 110)$ as compared to females $31.8 \%(35 / 110)$ and the male to female ratio was 2.1:1.

In Bader HA et $\mathrm{al}^{15}$ study, 80\% were males and 20\% were females and the male to female ratio was 4:1. In Tripathi BN et $^{16}$ study, there were 61 male and 30 female patients. The male:female ratio was approximately $2: 1$.

In Jeevangi BA et $\mathrm{a}^{17}$ study, there were 39 (73.6\%) males and $14(26.4 \%)$ female patients. Sawarkar K et al ${ }^{18}$ also observed in a similar study that majority were male patients (39, $84.78 \%)$ and there were only $7(15.22 \%)$ females patients.

Acute pancreatitis is more common in males ad our observations are in concordance with those of the above authors.
Clinical symptoms: In the present study, the most common clinical presentation was that of pain in epigastrium with vomiting and was seen in $40.9 \%$ (45/110) cases, followed by epigastric pain alone which was seen in $27.2 \%$ (30/110) cases. In the study by Raghuwanshi $\mathrm{S}$ et $\mathrm{al}^{19}$ symptoms and signs in patients of acute pancreatitis were a triad of epigastric pain, nausea and vomiting that was present in $75 \%$ of the patients. In the study by Sahu B et $\mathrm{a}^{20}$ the most common clinical presentation was of epigastric pain in 47 (78.3\%) patients, followed by vomiting in $46(76.7 \%)$ cases.

CT findings: In our study, the most common CT findings were of diffuse enlargement in $43.6 \%$ cases. In $63.6 \%$ cases there was irregular contour and focal hypodensity. Necrosis of $<30 \%$ parenchyma was seen in $29 \%$ cases.

In Bader HA et $\mathrm{al}^{15}$ study, the CT data classified acute pancreatitis into two types: interstitial edematous pancreatitis, which was recorded in 80 (80\%) patients, and as necrotizing pancreatitis with or without peripancreatic necrotic fluid, which was recorded in 20 (20\%) patients. Three patients with interstitial edematous acute pancreatitis changed to necrotic type in the follow-up.

In Raghuwanshi $\mathrm{S}$ et $\mathrm{al}^{19}$ study, most common CT findings were peri-pancreatic inflammatory changes in mesentery, greater omentum and transverse mesocolon (88\%). Second most common CT finding was of pancreatic contour irregularity (80\%). Twenty five patients (50\%) had necrosis of the pancreas with 14 of them having more than $50 \%$ necrosis.

Etiology of acute pancreatitis: In the present study, most common etiological factor was of gall stones and was seen in $31.8 \%(35 / 110)$, and the next common factor was alcoholism seen in $27.2 \%(30 / 110)$.

In Bader HA et $\mathrm{al}^{15}$ study, the first leading cause of acute pancreatitis was of gall bladder stones (biliary), found in 48 (48\%) patients, and second cause was alcohol abuse in 25 (25\%) patients, and the third cause was hyperlipidemia in $22(22 \%)$ patients and post-endoscopic retrograde cholangiopancreatography (ERCP) in five (5\%) patients.

In Jeevangi $\mathrm{BA}$ et $\mathrm{al}^{17}$ study, the most common cause of pancreatitis was attributed to chronic alcohol abuse in 32 cases.

In Raghuwanshi $\mathrm{S}$ et $\mathrm{al}^{19}$ study, most common etiological factors encountered were cholelithiasis (42\%) and alcoholism (38\%) followed by idiopathic (24\%), trauma (2\%) and drug induced (2\%).

In the study by Sahu B et $\mathrm{al}^{20}$ chronic alcohol abuse was the most common cause of acute pancreatitis $(n=30,50.0 \%)$, followed by gallstone disease ( $n=15,31 \%)$.

Biochemical investigations: In our study, amylase level was elevated in 59\% cases, whereas, lipase level was elevated in $80 \%$ cases.

In Bader HA et $\mathrm{a}^{15}$ study, amylase level less than or equal to $210 \mathrm{U} / 1$ was seen in 29 (29\%) patients and more than $210 \mathrm{U} / 1$ in $71(71 \%)$ patients, whereas lipase level less than or equal to $180 \mathrm{U} / 1$ in 20 (20\%) patients and more than $180 \mathrm{U} / 1$ in $80(80 \%)$ patients was seen. Sawarkar K et $\mathrm{al}^{18}$ in their study observed elevated serum lipase and serum amylase levels in all the cases. 
Correlation between Ranson's criteria and Balthazar's CTSI: In our study, there was a slight discordance between the results of Ranson's criteria and Balthazar's CTSI system. This discordance could be attributed to the fact that with CT scan images one can actually visualize the anatomic changes and also extension of the disease process within the pancreatic parenchyma and even into extrapancreatic tissues. This gives the advantage to CTSI imaging over Ranson's criteria. Similar observations were reported by Tripathi BN et $\mathrm{al}^{16}$ and Leung TK et al. ${ }^{21}$

Complications of acute pancreatitis: In the present study, Ascites and Pleural effusion was noted in 31.8\% cases each. In Raghuwanshi $\mathrm{S}$ et $\mathrm{al}^{19}$ study, pleural effusion was the most common extra-pancreatic complication with left pleural effusion being more common.

Sahu B et $\mathrm{a}^{20}$ observed that the most common complication in their study population was pleural effusion, seen in $30 / 60$ (50\%) cases, followed by ascites. Venous thrombosis (involving splenoportal axis) was the most common vascular complication, seen in 16/60 (27\%) patients.

\section{CONCLUSION}

Acute pancreatitis commonly affects adult males. CT scan plays an important role in diagnosing acute pancreatitis and Balthazar's CTSI system is advantageous over the Ranson's criteria system. The CT modality gives information on the severity and extent of the inflammatory process and thereby helps in decision making for patient management.

\section{REFERENCES}

1. Tenner S, Baillie J, DeWitt J, Vege SS. American College of Gastroenterology guideline: management of acute pancreatitis. Am J Gastroenterol 2015; 108(1):14001415.

2. Shuji Isaji TT, Kawarada Y, Koichi Hirata TM, Yoshida M, Sekimoto M, Hirota M, et al. JPN Guidelines for the management of acute pancreatitis: Surgical management. J Hepatobiliary Pancreat Surg. 2006;13(5):48-55.

3. Balthazar EJ, Freeny PC vanSonnenberg E. Imaging and intervention in acute pancreatitis. Radiology 1994;193(3):297-306.

4. Bharwani N, Patel S, Prabhudesai S. Acute pancreatitis: the role of imaging in diagnosis and management. Clin Radiol 2015; 66(2):164-175.

5. Banks PA, Conwell DL, Toskes PP. The management of acute and chronic pancreatitis. Gastroenterol Hepatol 2015; 6(6):1-16.

6. Cho JH, Kim TN, Chung HH, et al. Comparison of scoring systems in predicting the severity of acute pancreatitis. World J Gastroenterol 2015;21(8):23872394.

7. Zaheer A, Singh VK, Qureshi RO, Fishman EK. The revised Atlanta classification for acute pancreatitis: updates in imaging terminology and guidelines. Abdom Imaging 2016;38(4):125-136.

8. Sahu B, Abbey P, Anand R, Kumar A, Tomer S, Malik E. Severity assessment of acute pancreatitis using CT severity index and modified CT severity index: Correlation with clinical outcomes and severity grading as per the Revised Atlanta Classification. Indian J Radiol Imaging [Internet]. 2017;27(5):152-60.

9. Mortele KJ, Weisner W, Intriere L, Shankar S, Zou K, Kalantari BN, et al. A modified CT severity index for evaluating acute pancreatitis: improved correlation with patient out come.AJR. 2004; 183(5): 1261-65.

10. Balthazar EJ. Acute pancreatitis: assessment of severity with clinical and CT evaluation. Radiology 2002;223(3):603-13.

11. Balthazar EJ. Staging of acute pancreatitis. Radiol Clin North Am 2002;40(1):1199-209.

12. Merkle EM, Görich J. Imaging of acute pancreatitis. Eur Radiol 2002;12(6):1979-92.

13. Mendez Jr G, Isikoff MB, Hill MC. CT of acute pancreatitis: interim assessment. AJR Am J Roentgenol 1980;135(4):463-9.

14. Trout AT, Elsayes KM, Ellis JH, Francis IR. Imaging of acute pancreatitis: prognostic value of computed tomographic findings. J Comput Assist Tomogr 2010;34(2):485-95.

15. Badera HAM, Abd El Azeem AS. Role of computed tomography in diagnosis, follow-up, and minimally invasive treatment of acute pancreatitis. Sci J Al-Azhar Med Fac Girls 2018;2(1):52-57.

16. Tripathi BN, Sethi R, Pandey S. CT evaluation is must for prognosis prediction in acute pancreatitis; results of a two year prospective study. J. Evid. Based Med. Healthc 2018;5(28):2105-2109.

17. Jeevangi BA, Yeli RK, Borugadda R, Pyadala N. Management of Acute Pancreatitis by Using Modified Computed Tomography Severity Index International Journal of Contemporary Medicine Surgery and Radiology 2018;3 (1):91-95.

18. Sawarkar K, Shaha P, Narayan R, Chavan D, More D, Biyani A. Role of Computed Tomography in Predicting Severity of Acute Pancreatitis and its Correlation with Clinical Outcome. International Journal of Contemporary Medical Research 2019; 6(2):45.

19. Raghuwanshi S, Gupta R, Vyas MM, Sharma R. CT Evaluation of Acute Pancreatitis and its Prognostic Correlation with CT Severity Index Journal of Clinical and Diagnostic Research 2016;10(6): TC06-TC11.

20. Sahu B, Abbey P, Anand R, Kumar A, Tomer S, Malik E. Severity assessment of acute pancreatitis using CT severity index and modified CT severity index: Correlation with clinical outcomes and severity grading as per the Revised Atlanta Classification. Indian Journal of Radiology and Imaging 2017;27(6):152-60.

21. Leung TK, Lee CM, Lin SY, et al. Balthazar computed tomography severity index is superior to Ranson criteria and APACHE II scoring system in predicting acute pancreatitis outcome. World J Gastroenterol 2005;11(38):6049-6052.

\section{Source of Support: Nil; Conflict of Interest: None}

Submitted: 30-12-2019; Accepted: 25-01-2020; Published online: 24-02-2020 